\title{
Indicators of Achievement in EFL Classes at a Taiwanese University
}

\author{
Brent Allan Kelsen ${ }^{1}$ and Hsin-yi Liang ${ }^{2}$ \\ ${ }^{1}$ Language Center, Soochow University, Wai-Shuang Hsi, Taipei 111, Taiwan \\ ${ }^{2}$ Department of Child Psychiatry, Chang Gung Memorial Hospital Linkao Medical Center, \\ Chang Gung University College of Medicine, Tauyuan 333, Taiwan
}

Correspondence should be addressed to Hsin-yi Liang, sophie.lhy@gmail.com

Received 4 March 2012; Revised 15 July 2012; Accepted 15 July 2012

Academic Editor: Eric Z. F. Liu

Copyright ( 2012 B. A. Kelsen and H.-y. Liang. This is an open access article distributed under the Creative Commons Attribution License, which permits unrestricted use, distribution, and reproduction in any medium, provided the original work is properly cited.

Understanding the factors that contribute to student success is crucial for educators. This study estimated the indicators of success in the context of student achievement in university EFL courses in Taiwan. Data was collected from two classes of sophomore students and various student assessment aspects served as dependent variables: overall final grade, final exam score, oral test performance, and scores received on the listening, reading, and writing sections of the final exam. Explanatory variables included: years of English study, gender, part-time work, total hours studying English, participation in English-taught program, English language aptitude, first language ability, intrinsic motivation, extrinsic motivation, language anxiety, attendance, reading English for pleasure, and socioeconomic status. Pearson product-moment correlations were calculated and stepwise multiple regression analyses identified selections of variables that explained the dependent variables. Multiple regressions using the selected variables suggested that hours spent studying English, participation in the English taught program, first language ability, attendance and reading for pleasure were the most significant indicators of achievement. All models provided statistically significant moderate to strong explanatory power. Finally, this paper offers pedagogical considerations based on the results, as well as suggestions for future research.

\section{Introduction}

General English courses are a common feature of the university curriculum landscape in Taiwan. Most universities require students to enroll in EFL classes for at least the first two years. Needless to say, it is important for educators to understand the determinants of success associated with these classes.

This study focused on a relatively homogeneous group of Mandarin speakers enrolled in general English conversation classes at a Taiwanese university. To obtain more detailed data regarding this sample group, the dependent variables were established by decomposing student course performance into various components: overall final grade, final exam score, oral test, listening, reading, and writing sections of the final exam scores. Furthermore, this study was distinct in that it incorporated an eclectic range of variables likely to affect language achievement, thereby controlling for individual differences identified in the literature to be associated with both second language acquisition and other relevant disciplines: years spent studying English, gender, hours spent on part-time work, hours spent studying English per week, participation in English-taught courses, college entrance exam English score, first language ability, anxiety, intrinsic motivation, extrinsic motivation, attendance, reading English for pleasure, and socioeconomic status. This analysis employed class-level data from two classes of EFL students to calculate Pearson product-moment correlations, perform stepwise multiple regression procedures and run multiple regressions in order to reveal and evaluate the variables most closely correlated with success in the university EFL conversation courses under investigation.

Previous literature on the factors that influence second language acquisition success has identified a number of 
significant factors. Influential studies have conceptualized the impact of different aspects of motivation, anxiety, language aptitude, and self-confidence on achievement in language classes [1-6]. Generally, these researchers found that motivation, language aptitude, and self-confidence are positively correlated with student performance, while anxiety typically has a negative association. Although many of these studies focused on students studying European languages, Cheng et al. [5] assessed various types of anxiety in terms of the writing and speaking class grades of Mandarinspeaking English-majors in Taiwan, and established that these different types of anxiety affect spoken and written capabilities independently.

More recent research conducted in Taiwan has identified motivation and attitudes as significant variables explaining English proficiency $[7,8]$. In particular, Hsu [8] surveyed students enrolled in business English courses and reported positive effects for proficiency in terms of the motivation and attitude constructs under investigation, especially pertaining to the superior achievement of female students.

Further, the benefits of comprehensible input and the effects of reading for pleasure on improving student English ability [9] and writing performance $[10,11]$ have been well documented in the second language learning literature. These studies contended that reading for pleasure displayed significantly positive correlations with English learning performance within the Taiwan context.

While the influence of a student's first language on second language acquisition is complex and somewhat controversial, several studies have postulated that first language ability has positive effects on second-language comprehension, including apparent language processing benefits associated with reading in a second language $[12,13]$. Moreover, it has been suggested that language learners' use of their first language extends beyond mere translation-it serves as a cognitive function to enhance understanding [14].

Numerous scholars have also studied the predictors of success in mainstream university courses; they have identified a variety of predictors impacting student performance, including gender $[15,16]$, the effects of attendance [17-19], and the consequences of part-time work [20,21].

Condelli and Wrigley [22] cited the improved learning outcomes of students with higher attendance rates. As it is common knowledge that learning a foreign language requires significant time and dedication, it is surprising that the impact of class attendance and participation in classroom activities has received little attention thus far.

This study attempted to use an electric selection of variables identified in EFL and general course literature to address the following issues:

(1) Which variables are most closely correlated with the chosen aspects of student EFL achievement?

(2) Are there different indicators of success for different aspects of student achievement?

(3) Which covariates does the stepwise technique select to specify linear regression models of EFL achievement?
(4) How well do these models perform in explaining the variation in student achievement?

\section{Research Design}

2.1. Participants. The participants consisted of 74 students ( $n=56 ; 75.7 \%$ female) in two sophomore general English classes in 2009. The average age was 19.95. All students came from the School of Management, and their majors were accounting $(n=10 ; 13.5 \%)$, business administration $(n=$ $17 ; 23 \%)$, finance $(n=19 ; 25.7 \%)$, international business $(n=25 ; 33.8 \%)$, and management $(n=3 ; 4.1 \%)$.

2.2. Instruments. This study employed a number of variables. First, explanations of the response variables are provided, followed by descriptions of the explanatory variables.

\subsubsection{Dependent Variables}

Final Grade (Finalgrade). The final course grade for each student that participated in the study. Components of the final grade were attendance $(10 \%)$, participation $(10 \%)$, homework (10\%), midterm (30\%) and final (30\%) exams, and an oral test (10\%).

Final Exam Score (Finalexam). Student scores on the final exam taken on the last day of class. The final exam comprised of listening (30\%), reading (30\%) and writing (40\%) sections.

Oral Score (Oral). Oral score received based on a 10-minute oral test.

Listening Score (Listening). Student scores on the listening section of the final exam.

Reading Score (Reading). Student scores on the reading section of the final exam, which required students to read two articles, complete a cloze activity and answer multiple-choice questions.

Writing Score (Writing). Student scores on the writing section of the final exam, which called for two short compositions based on topics covered in the textbook.

\subsubsection{Explanatory Variables}

Years of English Study (Yearseng). The number of years the student had studied English formally, including pre-school, elementary school, junior and senior high school, and university.

Gender (gender). The students were coded as female $=0$ or male $=1$.

Part-Time Work (Jobhours). Hours per week spent on parttime employment. Twenty-five students had part-time jobs, 
accounting for 33.78 percent of all students. The mean and standard deviation for all students were 3.30 and 6.18, respectively, for the 25 students who were engaged in parttime employment, the mean and standard deviation were 9.78 and 7.10 , respectively.

Total Hours of English Studied per Week (Engtot). This variable indicates the total number of hours spent studying English outside of this class. This could include time spent participating in and studying for other English classes both at the university or at external cram schools, doing homework not associated with this class, and self study, among other sources.

English-Taught Program (Engtaught). Total number of class hours spent in the university's English-taught program, where students study other subjects in the business program and the medium of instruction is English. For all students in the study, the mean and standard deviation were 1.84 and 3.06, respectively. However, for the 27 students enrolled in the English-taught program, the mean and standard deviation were 5.04 and 3.08 , respectively.

English Aptitude (Jceeeng). Result attained on the English section of the Joint College Entrance Exam (JCEE). In Taiwan, the major route to enter university is by taking the Joint College Entrance Exam administered by the College Entrance Exam Center, held annually in January and July. The scores used in this study were those received in the January session of the JCEE. The minimum possible score was 1 and the maximum 15 .

First Language Ability (Jceechin). Mark achieved for the Chinese portion of the JCEE. The scores used in this study were those received in the January session of the JCEE. The minimum possible score was 1 and the maximum 15. All of the students in this study spoke Mandarin as their first language; therefore, first-language interference was assumed to be constant across all participants.

Anxiety (Anxiety). Five language learning anxiety items were measured using a 5-point Likert scale adapted from Cheng et al. [5]. The subitems for this construct were comfortable using English to do class activities, comfortable speaking to classmates in English, comfortable speaking to the teacher in English, confident writing in English, and confident giving a presentation in English. The maximum score of twentyfive signified a student who was confident using English in terms of the above sub-items, while the minimum score of five suggested a student who felt extreme anxiety in terms of using English.

Intrinsic Motivation (Intrinsic). Intrinsic motivation refers to the enjoyment, pleasure, or usefulness students associate with learning a language. Five items adapted from Deci and Ryan [1] and Noels et al. [23] were used to measure this construct: enjoyment derived from studying English, interest in English, use of English to learn about the cultures of other countries, use of English to communicate with friends, and perception of the importance of English as a global language. Participants rated each on a 5-point Likert scale. Students who exhibited a high level of intrinsic motivation would have registered a maximum score of twenty-five, while those with low intrinsic motivation would have recorded a minimum score of five.

Extrinsic Motivation (Extrinsic). Extrinsic motivation is concerned with external factors that motivate a student to learn, such as the earning of some reward or the avoidance of some punishment. This construct was measured using five items adapted from Deci and Ryan [1] and Noels et al. [23] using a 5-point Likert scale. The students rated statements referring to the importance of English for their future career, importance for their future study, enrollment in the English course due to it being compulsory, desire to achieve a good grade, and wish to avoid punishment if they fail their English course. Students with a high level of extrinsic motivation would have registered a maximum score of twenty-five, while those with low extrinsic motivation would have recorded a minimum score of five.

Attendance (Attend). Attendance was based on class attendance records for the 16 classes held that semester, which accounted for 10 percent of students' final grades. For this study, attendance required both presence in the classroom and conscious participation in class activities. The minimum number of classes attended was 12 and the maximum number of classes attended was 16 .

Reading English for Pleasure (Readpleas). Total hours students spent per week reading English materials (books, magazines, newspapers, etc.) for personal pleasure. Student scores were recorded using a 5-point Likert scale ranging from 1 (no reading for pleasure) to 5 (read for pleasure on a daily basis).

Socioeconomic Status (Socecon). Socioeconomic status is a measure of a person's income, education and wealth. This study used student perceptions of their family's wealth and their father's level of education as the measurements for this variable. The variables were measured categorically and coded on a scale of 1 to 5 . Regarding family wealth, 1 represented poor and 5 represented rich; for level of education, 1 equaled no high school education, 2 completed high school, 3 a bachelor's degree, 4 a master's degree, and 5 a doctorate. The maximum possible score for these variables was 10 and the minimum 2 .

2.3. Procedure. This study used class-level data collected from class records and an in-class student survey to explore the association and influence of a variety of explanatory variables on different measures of student assessment. The survey was conducted on the final day of class (week 17) of an 18 -week semester and took approximately 10 minutes to complete. Of the 79 questionnaires collected, there were 74 valid, complete responses. 
TABLE 1: Dependent variable means and standard deviations.

\begin{tabular}{lcccccc}
\hline Variable & Total mean & S.D. & Female mean & S.D. & Male mean & S.D. \\
\hline Final grade & 74.32 & $(8.89)$ & 76.21 & $(7.78)$ & $(9.74)$ \\
Final exam & 68.26 & $(11.72)$ & 69.84 & $(11.18)$ & 63.41 & $(12.32)$ \\
Oral & 76.77 & $(6.29)$ & 77.80 & $(5.63)$ & 73.56 & $(7.27)$ \\
Listening & 57.07 & $(18.35)$ & 58.52 & $(17.56)$ & 52.58 & $(20.51)$ \\
Reading & 73.85 & $(6.89)$ & 74.13 & $(10.84)$ & $(5.99)$ \\
Writing & 73.05 & $(11.72)$ & 74.7 & & 67.93 & $(12.24)$ \\
\hline
\end{tabular}

TABLE 2: Explanatory variable means and standard deviations.

\begin{tabular}{|c|c|c|c|c|c|c|}
\hline Variable & Total mean & S.D. & Female mean & S.D. & Male mean & S.D. \\
\hline Yearseng & 10.03 & $(2.16)$ & 10.10 & $(2.22)$ & 9.83 & $(2.01)$ \\
\hline Engtotal & 5.16 & $(4.19)$ & 5.03 & $(4.37)$ & 5.56 & $(3.67)$ \\
\hline Engtaught & 1.84 & $(3.06)$ & 1.84 & $(3.07)$ & 1.83 & (3.11) \\
\hline Jobhours & 3.30 & $(6.18)$ & 3.69 & $(6.70)$ & 2.11 & $(4.16)$ \\
\hline Jceeeng & 12.81 & $(1.45)$ & 12.96 & $(1.55)$ & 12.33 & $(0.97)$ \\
\hline Jceechin & 12.31 & $(1.20)$ & 12.43 & $(1.25)$ & 11.94 & $(1.00)$ \\
\hline Anxiety & 15.80 & $(3.09)$ & 15.91 & $(3.26)$ & 15.44 & $(2.55)$ \\
\hline Intrinsic & 18.20 & $(4.26)$ & 18.52 & $(4.09)$ & 17.17 & $(4.74)$ \\
\hline Extrinsic & 20.90 & $(2.08)$ & 21.00 & $(2.09)$ & 20.44 & $(2.06)$ \\
\hline Attend & 14.74 & $(1.22)$ & 14.82 & $(1.24)$ & 14.50 & $(1.15)$ \\
\hline Readpleas & 3.08 & $(1.32)$ & 3.03 & $(1.22)$ & 2.39 & $(1.42)$ \\
\hline Socecon & 6.15 & $(0.92)$ & 6.07 & $(0.95)$ & 6.39 & $(0.78)$ \\
\hline
\end{tabular}

2.4. Data Analysis. Initially, this study calculated Pearsonproduct moment correlation coefficients and corresponding $P$ values for combinations of the dependent and independent variables considered with the intention of exploring their strength and significance. Next, the investigation used stepwise regression analyses to determine which of the variables were selected to "best" explain the variation in the dependent variables. The stepwise regressions employed backward and forward selection processes using the Akaike [24] information criteria (AIC). This procedure selected a plausible model that balanced the goodness of fit with the number of explanatory variables. Finally, multiple regressions were performed using linear least squares models of the form: $Y=\alpha+\beta X+\varepsilon$. Accordingly, dependent variables were depicted by $Y$, with $\alpha$ the intercept and $\beta$ the slope of the regression equation. $X$ represented a vector of explanatory variables and $\varepsilon$ the error term. One advantage of using such a multiple regression model was its capacity to account for individual effects particular to each student by including them in the vector of explanatory variables. The statistical software package $\mathrm{R}$ [25] was used to estimate all statistics presented in this study.

\section{Results and Discussion}

The dependent variable means and standard deviations are summarized in Table 1. From this it is evident that on average females scored higher than their male counterparts on all aspects of course performance. Table 2 provides a summary of the means and standard deviations of the independent variables. Here we observe that on average females had studied more years of English, worked more job hours, had higher college entrance scores for Chinese and English, recorded higher anxiety and intrinsic and extrinsic motivation, attended slightly more classes and read more for pleasure.

One of the central purposes of this investigation was to explore the relationships between the dependent variables measuring different aspects of student achievement and a number of explanatory variables identified in the literature. From Table 3, it is evident that all of the explanatory variables (apart from yearseng and jobhours) show moderate significant correlations with at least one of the dependant variables. The Chronbach's alpha values measuring the internal consistency for the items of the anxiety, intrinsic, and extrinsic constructs were $0.84,0.95$, and 0.74 , respectively.

This study applied stepwise regression analysis to each dependent variable with the set of independent variables and utilized the variables selected to conduct multiple regression analyses. The coefficients and statistical significance for each variable, as well as the explanatory power and significance for the model, are reported in Tables 4 and 5. F-statistics show all of the models to be highly significant. Furthermore, the explanatory power of the models ranged from 0.436 to 0.594 , which is reasonable for an observational study such as this.

The results of this study show that there was a relatively large difference in terms of achievement between females and males. This difference was significant for the correlations with finalgrade, finalexam, oral, and writing. However, in the multiple regressions, even though gender was a commonly 
TABLE 3: Correlations between dependent and independent variables.

\begin{tabular}{lllllll}
\hline Variable & Final grade & Final exam & Oral & Listening & Reading & Writing \\
\hline Yearseng & -0.007 & 0.114 & 0.026 & 0.083 & -0.024 & 0.11 \\
Gender & $-0.379^{* * *}$ & $-0.24^{*}$ & $-0.291^{*}$ & -0.14 & -0.07 & $-0.254^{*}$ \\
Jobhours & 0.106 & 0.077 & 0.003 & 0.115 & 0.165 & 0.034 \\
Engtotal & $0.285^{*}$ & $0.331^{* *}$ & 0.19 & $0.297^{* *}$ & 0.215 & $0.279^{*}$ \\
Engtaught & $0.330^{* *}$ & $0.291^{*}$ & $0.273^{*}$ & $0.261^{*}$ & 0.166 & $0.246^{*}$ \\
Jceeeng & $0.376^{* * *}$ & $0.305^{* *}$ & $0.344^{* *}$ & $0.364^{* *}$ & $0.469^{* * *}$ & 0.197 \\
Jceechin & $0.539^{* * *}$ & $0.548^{* * *}$ & $0.496^{* * *}$ & $0.501^{* * *}$ & $0.561^{* * *}$ & $0.457^{* * *}$ \\
Intrinsic & $0.302^{* *}$ & 0.15 & $0.349^{* *}$ & 0.07 & $0.34^{* *}$ & 0.17 \\
Extrinsic & $0.405^{* * *}$ & $0.314^{* *}$ & $0.338^{* *}$ & $0.329^{* *}$ & $0.376^{* * *}$ & $0.232^{*}$ \\
Anxiety & $0.232^{* *}$ & $0.272^{*}$ & 0.085 & $0.25^{*}$ & $0.41^{* * *}$ & 0.225 \\
Attend & $0.349^{* *}$ & $0.419^{* * *}$ & $0.257^{*}$ & $0.35^{* *}$ & $0.268^{*}$ & $0.372^{* *}$ \\
Readpleas & $0.472^{* * *}$ & $0.371^{* *}$ & $0.493^{* * *}$ & 0.21 & $0.343^{* *}$ & $0.397^{* * *}$ \\
Socecon & 0.19 & 0.14 & 0.222 & 0.216 & $0.259^{*}$ & 0.064 \\
\hline
\end{tabular}

*** $P$ value $<0.001,{ }^{*} P$ value $<0.01$, and $* P$ value $<0.05$.

TABLe 4: Regressions for dependent variables: finalgrade, finalexam, and oral.

\begin{tabular}{llllll}
\hline \multicolumn{2}{r}{ Final grade } & \multicolumn{2}{c}{ Final exam } & \multicolumn{2}{c}{ Oral } \\
Variable & Coefficient & Variable & Coefficient & Variable & Coefficient \\
\hline Intercept & $8.264(0.77)$ & Intercept & $-22.783(-1.602)$ & Intercept & $37.353^{* * *}(5.508)$ \\
Gender & $-4.966^{* *}(-2.864)$ & Gender & $-3.262(-1.37)$ & Gender & $-2.24(-1.679)$ \\
Engtaught & $0.831^{* * *}(3.645)$ & Engtotal & $0.76^{* *}(3.257)$ & Jobhours & $-0.138(-1.527)$ \\
Jceechin & $2.914^{* * *}(4.751)$ & Jceeeng & $-2.401^{*}(-2.356)$ & Engtotal & $-0.313(-1.552)$ \\
Attend & $1.109(1.85)$ & Jceechin & $5.873^{* * *}(4.717)$ & Engtaught & $0.798^{* *}(2.976)$ \\
Readpleas & $1.639^{* *}(2.839)$ & Attend & $2.824^{* *}(3.431)$ & Jceechin & $2.256^{* * *}(4.738)$ \\
Socecon & $1.375(1.72)$ & Readpleas & $1.541(1.95)$ & Readpleas & $1.512^{* *}(3.365)$ \\
\hline$R^{2}$ & & & & Socecon & $1.322^{*}(2.118)$ \\
Adj $R^{2}$ & 0.594 & & 0.547 & & 0.524 \\
$F$ ratio & $16.3^{* * *}$ & & 0.506 & $13.45^{* * *}$ & 0.474 \\
df & 6,67 & & 6,67 & & $10.39^{* * *}$ \\
\hline
\end{tabular}

$* * * P$ value $<0.001, * * P$ value $<0.01$, and $* P$ value $<0.05$.

Values in parentheses are $t$ values.

selected variable, it only showed significance in estimating finalgrade. Nevertheless, this finding appears to suggest the emergence of a general pattern whereby male students are not keeping pace with their female counterparts. Such findings mirror the results of numerous other recent studies $[16,19]$.

The total number of hours of English study per week was significantly correlated with scores on the final exam, and the listening, and writing sections. Moreover, those students enrolled in the English-taught program received higher final grades and scores on the oral test. For the multiple regression analyses, either variable engtot or engtaught, or the combination of both variables was significant in explaining the variation for all of the explanatory variables except reading. Generally, the 27 students enrolled in the Englishtaught program would be expected to possess superior English skills by virtue of their selection for the Englishtaught program and greater degree of English immersion. Nevertheless, both of these results suggest that the more students are exposed to the target language, the more their language skills improve.

First language aptitude, as measured by the JCEE Chinese exam, was closely related to achievement in all of areas of English assessment, for both the correlations and multiple regressions, lending support to the hypotheses of previously mentioned authors [12-14]. Somewhat surprisingly, using 
TABLE 5: Regressions for dependent variables: listening, reading, and writing.

\begin{tabular}{|c|c|c|c|c|c|}
\hline \multicolumn{2}{|c|}{ Listening } & \multicolumn{2}{|c|}{ Reading } & \multicolumn{2}{|c|}{ Writing } \\
\hline Variable & Coefficient & Variable & Coefficient & Variable & Coefficient \\
\hline Intercept & $\begin{array}{l}-116.4^{* * *} \\
(-4.105)\end{array}$ & Intercept & $19.111^{*}(2.499)$ & Intercept & $-0.651(-0.043)$ \\
\hline Yearseng & $1.120(1.4)$ & Jceechin & $2.572 * * *(4.76)$ & Gender & $-3.822(-1.521)$ \\
\hline Engtotal & $0.996^{*}(2.365)$ & Anxiety & $0.5741^{* *}(2.790)$ & Engtotal & $0.646^{*}(2.623)$ \\
\hline Jceechin & $6.611^{* * *}(4.176)$ & Readpleas & $0.757(1.573)$ & Jceeeng & $-3.011^{* *}(-2.8)$ \\
\hline Extrinsic & $1.6(1.721)$ & Socecon & $1.898^{* *}(2.843)$ & Jceechin & $5.424^{* * *}(4.129)$ \\
\hline Intrinsic & $-0.815(-1.828)$ & & & Attend & $2.526^{* *}(2.909)$ \\
\hline Attend & $2.554(1.728)$ & & & Readpleas & $1.899 *(2.277)$ \\
\hline Socecon & $3.176(1.541)$ & & & & \\
\hline$R^{2}$ & 0.436 & & 0.473 & & 0.474 \\
\hline $\operatorname{Adj} R^{2}$ & 0.376 & & 0.442 & & 0.427 \\
\hline$F$ ratio & $7.285^{* * *}$ & & $15.48^{* * *}$ & & $10.06^{* * *}$ \\
\hline df & 7,66 & & 4,69 & & 6,67 \\
\hline
\end{tabular}

*** $P$ value $<0.001, * * P$ value $<0.01$, and $* P$ value $<0.05$.

Values in parentheses are $t$ values.

the JCEE English exam scores as an instrument for English aptitude resulted in significant but negative coefficients for the finalexam, and writing dependent variables. One potential reason for this result, especially with regard to listening and oral scores, could be that the JCEE English exam does not include listening or speaking sections, both of which made up integral parts of the college English course considered in this study. Rightfully, the examination authorities are taking steps to remedy this situation [26]. Furthermore, the means of instruction and form of student learning at tertiary institutions may differ significantly from those associated with secondary education, as students face situations where they cannot rely as heavily on rote memorization and are required to actively participate in and take increased responsibility for their learning. Nonetheless, it is necessary to sound a note of caution regarding the inclusion of jceeeng as an explanatory variable given its high colinearity with jceechin, which could lead to instability in terms of the regression coefficient estimates.

Attendance was significantly positively correlated with final exam sores, and the writing section of the final exam. Such a result implies that students benefit from attending class, as concluded by other studies [17-19, 22]. This result seems intuitive given that language learning is commonly perceived to require participation and practice over extended periods of time.

The significant correlations between reading for pleasure and final grades, oral test scores and the written section of the final exam correspond with those found in previously mentioned studies [8-10]. Indeed, the results further confirm that reading for pleasure has positive benefits for many aspects of student English achievement.

\section{Conclusions and Implications}

The results of this research identify a number of variables associated with success in the university EFL course under consideration. These results can be divided into two distinct sections.

(1) The Pearson-product moment correlations point to a variety of variables that can indicate success: female gender, total hours of English study per week, enrollment in the English-taught program, English aptitude, first language ability, intrinsic motivation, extrinsic motivation, class attendance, and reading for pleasure. Of these variables, first language ability was the most closely correlated with all of the components of attainment. Nevertheless, as a coefficient of determination (correlation squared), its predictive power is relatively modest.

(2) Stepwise regression selects combinations of variables that "best" explain the variation in the response variable. Although the indicators of success vary depending on the dependent variable under consideration, the results of this study generally point to total hours spent studying English per week (either in other English classes or English-taught courses), first language ability, attendance in class, and reading for pleasure as indicating those students most likely to achieve proficiency in the general university English classes considered in this research.

This study gives rise to a number of pedagogical implications. First, it is important for educators to consider gender differences and make efforts to support male student achievement. Second, students should be encouraged to engage in supplementary English learning. This could range from additional formal English courses and informal elective class environments to self-access learning and meaningful homework assignments. Third, perhaps the common policy of placing students into freshman English classes based on their JCEE English scores ought to be reviewed in light of the importance of first language ability as an indicator of achievement. It may be pertinent to include JCEE Mandarin 
scores in this equation. Fourth, providing clear, stringent attendance policies may be utilized to promote attendance in English classes. Fifth, encouraging students to read English materials of interest appears to be beneficial in advancing student achievement.

It should also be noted that even though the motivation and anxiety constructs did not provide notable explanatory power with reference to the dependent variables used in this study subsequent to the inclusion of other variables, they were significantly correlated with a majority of the dependent variables and should not be overlooked as important factors in successful English language learning. Further research is required to shed light on the specific motivational constructs that affect students enrolled in EFL courses in Taiwanese universities.

The implications of this research are constrained by a number of limitations. First, the self-reported nature of the questionnaire employed and the fact that it was conducted in English are limiting factors. However, the high-intermediate/low-advanced level of the students and availability of the course instructor to help with any questions mitigate these concerns to a large extent. Second, the sample coming from a relatively small group of students (especially male participants) who were all business majors means the generalizability of the results presented here needs to be treated with caution. In response to these limitations, the homogeneity of the sample of all business students should mitigate confounding factors to a certain extent, and exploration of the residuals preformed after the regressions displayed no concerns over the assumption of normality for the linear models used in this analysis. Finally, due to the scale of the project, some pertinent variables, such as learning strategies, metacognitive strategies, and general intelligence, were not included in the study. Future research is warranted to systematically address these issues.

Continuing research into the influences of success in university EFL courses will result in a better understanding of the factors that affect student performance, which in turn will assist educators as they develop curricula and implement policies that lead to greater student accomplishment. It is hoped that this paper may offer a first step in the search for the most meaningful indicators of success and motivate other researchers to continue studies in this direction.

\section{Acknowledgment}

An earlier version of this paper was presented at the Foreign Language Symposium, Foreign Language Center, Soochow University, March 2011.

\section{References}

[1] E. Deci and R. Ryan, Intrinsic Motivation and Self-determination in Human Behavior, Plenum, New York, NY, USA, 1985.

[2] R. C. Gardner, Social Psychology and Second Language Learning: The Role of Attitudes and Motivation, Edward Arnold, London, UK, 1985.

[3] Z. Dörnyei, "Motivation and motivating in the foreign language classroom," Modern Language Journal, vol. 78, no. 3, pp. 273-284, 1994.
[4] R. C. Gardner, P. F. Tremblay, and A.-M. Masgorét, "Towards a full model of second language learning: an empirical investigation," Modern Language Journal, vol. 81, pp. 344-362, 1997.

[5] Y. S. Cheng, E. K. Horwitz, and D. L. Schallert, "Language anxiety: differentiating writing and speaking components," Language Learning, vol. 49, no. 3, pp. 417-446, 1999.

[6] R. C. Gardner, "Correlation, causation, motivation, and second language acquisition," Canadian Psychology, vol. 41, no. 1, pp. 10-24, 2000.

[7] C. Chang, S. Liu, and Y. Lee, "A study of language learning strategies used by college EFL learners in Taiwan," pp. 235-262, July 2007, http://www.mdu.edu.tw/ ged/other\% 20download/bulletin/20070319/11.pdf.

[8] S. Hsu, "Business English learning motivation and effort on proficiency among junior college students," Nanya Education Report, no. 25, pp. 119-131, 2005, http://ir.lib.tiit .edu.tw/handle/987654321/124.

[9] S. Krashen, "Extensive reading in English as a foreign language by adolescents and young adults: a meta-analysis," International Journal of Foreign Language Teaching, vol. 3, no. 2, pp. 23-29, 2007.

[10] S. Y. Lee and S. Krashen, "Predictors of success in writing in English as a foreign language: reading, revision behavior, apprehension, and writing," The College Student Journal, vol. 36, no. 4, pp. 532-543, 2002.

[11] S. Y. Lee, "Facilitating and inhibiting factors in english as a foreign language writing performance: a model testing with structural equation modeling," Language Learning, vol. 55, no. 2, pp. 335-374, 2005.

[12] V. Cook, "Evidence for multicompetence," Language Learning, vol. 42, no. 4, pp. 557-591, 1992.

[13] T. A. Upton and L. Lee-Thompson, "The role of the first language in second language reading," Studies in Second Language Reading, vol. 23, pp. 469-495, 2001.

[14] R. G. Kern, "The role of mental translation in second language reading," Studies in Second Language Acquisition, vol. 16, pp. 441-461, 1994.

[15] S. J. Gibb, D. M. Fergusson, and L. J. Horwood, "Gender differences in educational achievement to age 25," Australian Journal of Education, vol. 52, no. 1, pp. 63-80, 2008.

[16] J. Liu and J. Chen, "The equalization pattern and process of gender educational inequality in Taiwan: some evidence for the threshold hypothesis," Journal of US_China Public Administration, vol. 6, no. 5, pp. 52-61, 2009.

[17] H. Park and P. Kerr, "Determinants of academic performance: a multinomial logit approach," Journal of Economic Education, vol. 21, pp. 101-111, 1990.

[18] J. R. Rodgers, "A panel-data study of the effect of student attendance on university performance," Australian Journal of Education, vol. 45, no. 3, pp. 284-295, 2001.

[19] T. F. Lin and J. Chen, "Cumulative class attendance and exam performance," Applied Economics Letters, vol. 13, no. 14, pp. 937-942, 2006.

[20] M. H. Salisbury and R. D. Padgett, "Examining the effects of work on college student experiences and liberal arts outcomes," in Proceedings of the 49th annual Association of Institutional Research Forum, Atlanta, Ga, USA, June 2009.

[21] G. R. Pike, G. D. Kuh, and R. C. Massa-McKinley, "First-year students' employment, engagement, and academic achievement: untangling the relationship between work and grades," Journal of Student Affairs Research and Practice, vol. 45, no. 4, pp. 560-582, 2008. 
[22] L. Condelli and H. Wrigley, "Instruction, language and literacy: what works study for adult ESL literacy students," 2003, http://lotos.library.uu.nl/publish/articles/000176/bookpart.pdf.

[23] K. A. Noels, R. Clément, and L. G. Pelletier, "Intrinsic, extrinsic, and integrative orientations of French Canadian learners of English," Canadian Modern Language Review, vol. 57, no. 3, pp. 424-440, 2000.

[24] H. Akaike, "A new look at the statistical model identification," IEEE Transactions on Automatic Control, vol. 19, no. 6, pp. 716-723, 1974.

[25] R Development Core Team, "R: a language and environment for statistical computing, reference index version 2.11.1," $\mathrm{R}$ Foundation for Statistical Computing, Vienna, Austria, 2005, http://www.r-project.org/.

[26] Taipei Times, "CEEC to introduce new English test for high school students," 2010, http://www.taipeitimes.com/ News/taiwan/archives/2010/12/28/2003492078. 


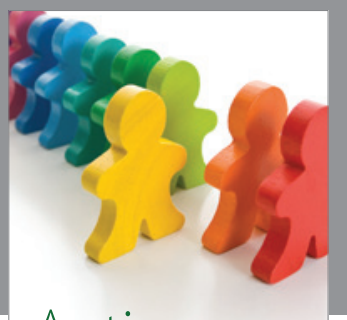

Autism

Research and Treatment
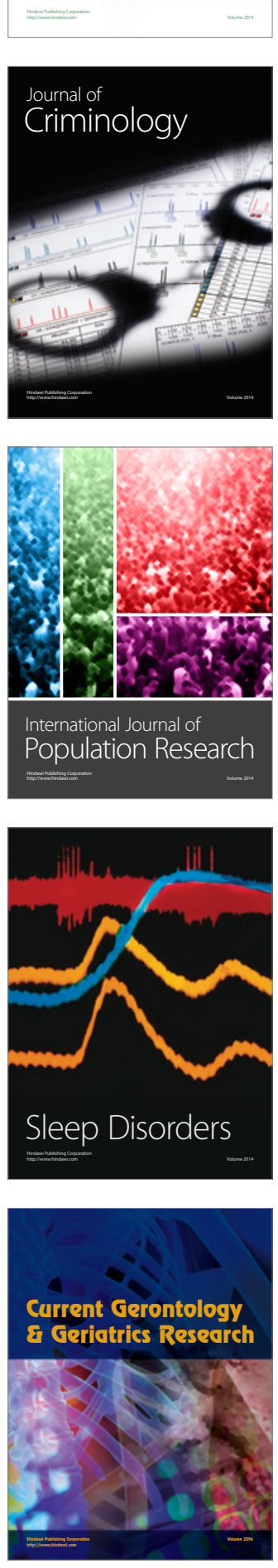
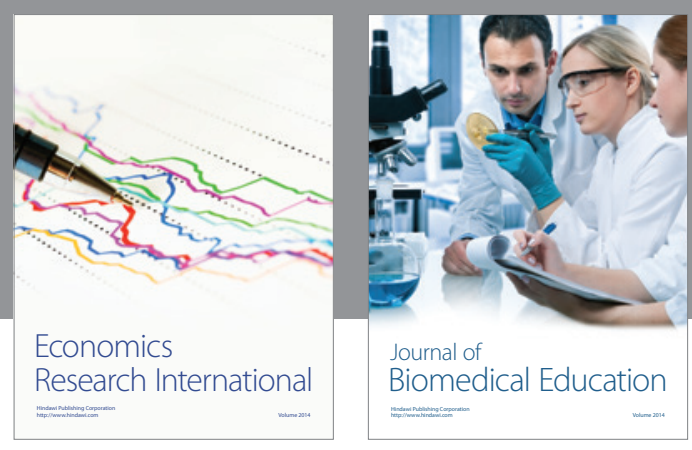

Journal of

Biomedical Education

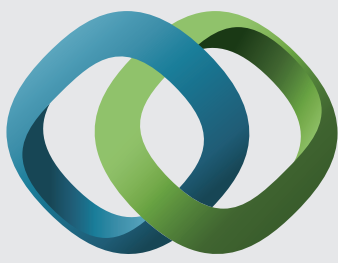

\section{Hindawi}

Submit your manuscripts at

http://www.hindawi.com
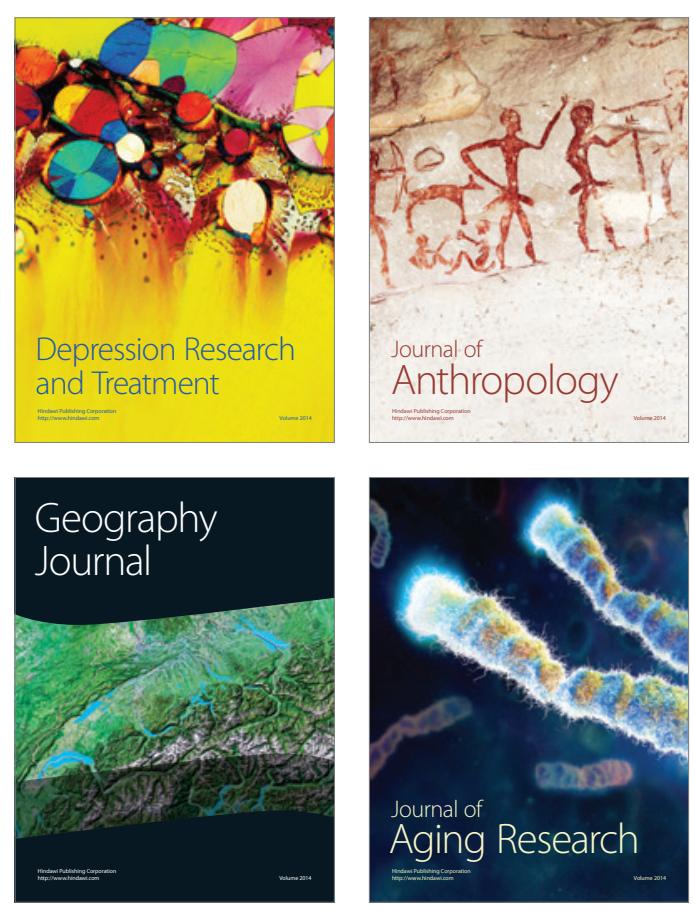

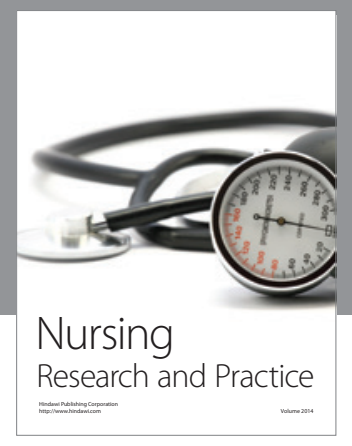

Nursing

Research and Practice

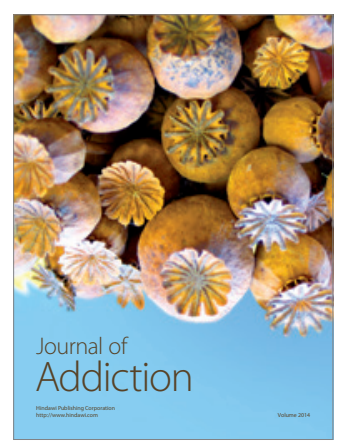

Child Development

Research

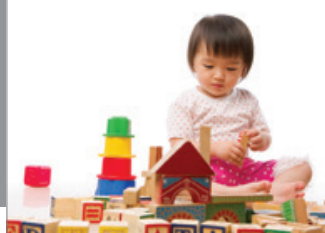

迥
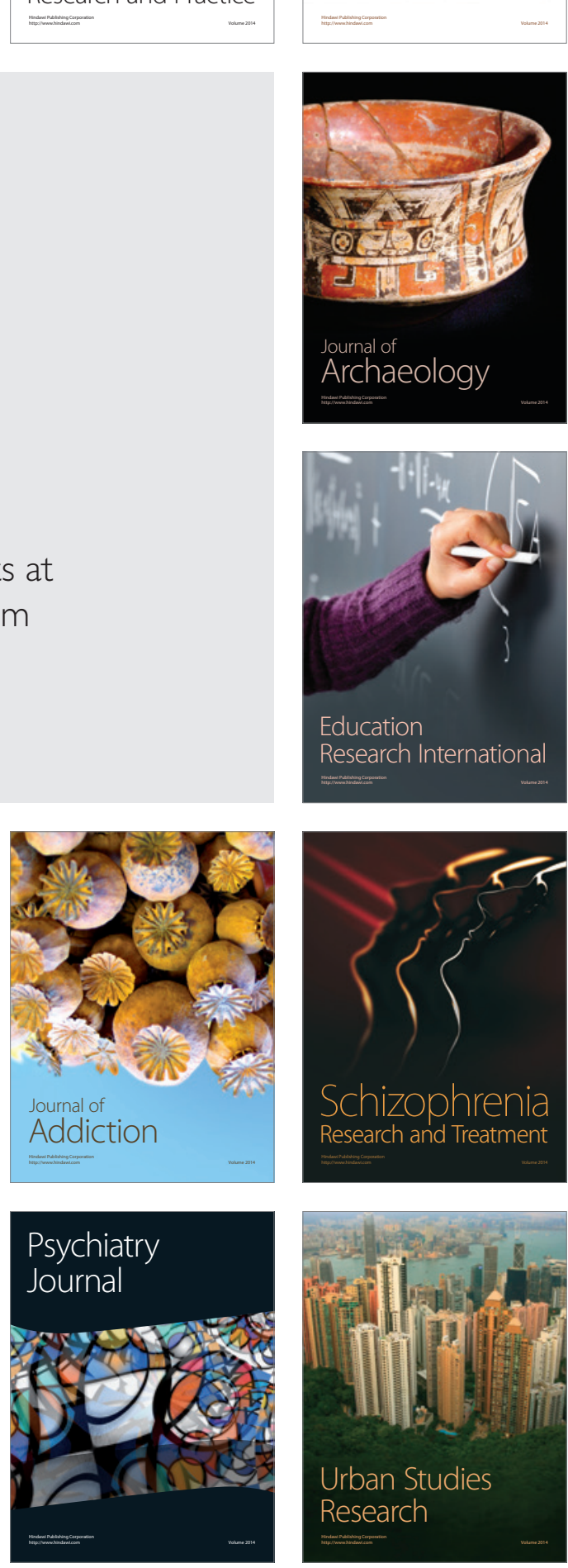